\title{
Intra-articular facet joint injections for low back pain: a systematic review
}

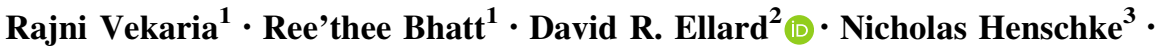 \\ Martin Underwood ${ }^{2} \cdot$ Harbinder Sandhu ${ }^{2}$
}

Received: 16 September 2015/Revised: 30 January 2016/Accepted: 31 January 2016/Published online: 23 February 2016 (C) The Author(s) 2016. This article is published with open access at Springerlink.com

\begin{abstract}
Purpose Evidence supporting the use of therapeutic intra-articular facet joint injections for patients with suspected facet joint pain is sparse. A systematic review including a narrative synthesis was carried out to determine if intra-articular facet joint injections with active drug are more effective in reducing back pain and back pain-related disability than a sham procedure or a placebo/inactive injection. Secondly, to determine if intra-articular facet joint injections with active drug or placebo/inactive
\end{abstract}

Rajni Vekaria and Ree'thee Bhatt are joint first authors.

Electronic supplementary material The online version of this article (doi:10.1007/s00586-016-4455-y) contains supplementary material, which is available to authorized users.

\footnotetext{
David R. Ellard

d.r.ellard@warwick.ac.uk

Rajni Vekaria

R.Vekaria@warwick.ac.uk

Ree'thee Bhatt

R-T.Bhatt@warwick.ac.uk

Nicholas Henschke

henschke@uni-heidelberg.de

Martin Underwood

m.underwood@warwick.ac.uk

Harbinder Sandhu

Harbinder.K.Sandhu@warwick.ac.uk

1 Warwick Medical School, The University of Warwick, Gibbet Hill Road, Coventry CV4 7AL, UK

2 Warwick Clinical Trials Unit, The University of Warwick, Gibbet Hill Road, Coventry CV4 7AL, UK

3 Institute for Public Health, University of Heidelberg, Im Neuenheimer Feld 324, 69120 Heidelberg, Germany
}

injection are more effective in reducing back pain and back pain-related disability than conservative treatment.

Methods Medline, EMBASE, CINAHL, CENTRAL, Index to Chiropractic Literature and the Cochrane Central Register of Controlled Trials were searched from inception through April 2015. Data were screened and single extraction with independent verification and risk of bias assessment was performed.

Results A total of 391 records were screened, and six trials were included. The trials included were small (range 18-109 participants) and overall in terms of pain and disability outcomes most were inconclusive. Only two of the trials report any significant between-group differences in pain (mean difference $-1.0,95 \% \mathrm{CI}-2.0$ to -0.1 ) and $(p=0.032)$ or disability (mean difference $-3.0,95 \% \mathrm{CI}$ -6.2 to 0.2$)$ and $(p=0.013)$ outcomes.

Conclusions The studies found here were clinically diverse and precluded any meta-analysis. A number of methodological issues were identified. The positive results, whilst interpreted with caution, do suggest that there is a need for further high-quality work in this area.

Keywords Systematic review - Intra-articular facet joint injections · Low back pain · Disability

\section{Background}

Low back pain continues to be responsible for more years lived with disability than any other disorder [1]. Multiple international studies attest to the massive health care and societal costs of low back pain [2]. Most of those affected have non-specific low back pain [3].

Low back pain can arise from the synovial facet joints [4]. Facet joint injury can occur from mechanical damage 
due to compressive forces or extensive stretching; degenerative changes such as osteoarthritis and inflammatory processes including rheumatoid arthritis [5, 6]. Facet joints are richly innervated by the medial branches from the dorsal rami above and below each joint [7]. The proportion of people affected by low back pain for whom facet joint pain is a contributing factor is unclear. In an interventional pain management practice study the prevalence of chronic back pain being caused by facet joints was reported to be $31 \%$ [8].

It is plausible that people whose low back pain is arising, at least in part, from facet joints is a sub-group for whom specific local treatment might be effective. The role of interventional procedures, such as intra-articular facet joint injections, in the management of low back pain is not clear. It is intra-articular injections for facet joint pain that are the focus of this review. Guidelines in both the UK and USA have not supported the use of intra-articular facet joint injections because of the absence of evidence to support their use $[3,9,10]$. Nevertheless, they are still widely used. Previous reviews of interventional procedures for low back pain have included multiple procedures and some have included both diagnostic and therapeutic injections. To aid our understanding of the possible role of intra-articular facet joint injection we have, in this review, focussed just on therapeutic intra-articular facet joint injections and have extended our interpretation to include consideration of the different populations recruited and differences in the comparator groups in our excluded studies.

Corticosteroids are established anti-inflammatory agents with demonstrable, short-term, benefits when injected intra-articularly to treat shoulder impingement syndrome or osteoarthritis of peripheral joints [11-15]. Intra-articular corticosteroid injections are beneficial in rheumatoid arthritis and have been shown to provide symptomatic relief for up to 3 months duration [16].

At a molecular level, corticosteroids may alter the transcription of pro-inflammatory genes [17]. The pain may originate from an inflammatory process occurring within the synovial joint or on the articular surfaces of the facet joints [18]. By reducing the levels of inflammation in or around the facet joint, there will be a reduction in the release of inflammatory mediators, which may be acting directly on the receptors or sensitising them to provoke a response.

With the success of corticosteroid injections in other joints and a firm knowledge of the mechanism of action of corticosteroids, it is reasonable to hypothesise that the same benefit could be delivered in another synovial joint, i.e. the facet joints. Furthermore, any symptom relief may facilitate adherence to physiotherapy or an exercise programme designed to improve lumbar range of movement and muscular stability [19].
Interpreting research data on treatment for facet joints needs to take into account how the exact research question being addressed impacts on study design and interpretation of the results. There are substantial challenges in arriving at a clinical diagnosis of probable facet joint pain; and hence, who should be considered for facet joint injections [20]. For a confirmed diagnosis, a positive diagnostic injection of local anaesthetic is required [21]. For studies of treatments for facet joint injections either clinical assessment or a positive diagnostic procedure can be used to define entry criteria. Intraarticular facet joint injections can be evaluated pragmatically by testing their effectiveness when they are compared with a conservative treatment (or no treatment). Alternatively they can be evaluated in more explanatory studies where they are compared to a placebo control or to a sham procedure.

We report a systematic review of randomised controlled trials of therapeutic intra-articular lumbar facet joint injections.

Specifically our objectives were:

1. To determine if facet joint injections with active drug are more effective in reducing back pain and back pain-related disability than a sham procedure or a placebo/inactive injection.

2. To determine if facet joint injections with active drug or placebo/inactive injection are more effective in reducing back pain and back pain-related disability than conservative treatment.

\section{Methods}

\section{Types of studies}

We prospectively registered our systematic review with the International Prospective Register of Systematic Reviews (PROSPERO) (CRD42015018991) http://www.crd.york.ac. uk/PROSPERO/display_record.asp?ID=CRD42015018991.

We only included RCTs of therapeutic interventions; we excluded studies of diagnostic injections alone.

\section{Types of participants}

Male and female patients aged 18 or over reporting symptoms of acute ( $<6$ weeks), sub-acute ( $6-12$ weeks), or chronic (12 weeks or more) back pain.

\section{Types of interventions}

We only included studies on injections into or around the facet joints. Injections into other areas were excluded.

Sham procedures were defined as any procedure whereby the participant had believed a corticosteroid had been 
injected into their facet joints. This may include inserting a needle into the facet joint, but not injecting a substance or using a device to replicate the sensation of a needle.

A placebo was defined as being any inert substance injected into or around the facet joint which may include saline.

Conservative therapy included the following interventions:

- Oral or topical medications.

- Corticosteroid injections other than into the facet joints.

- Physical therapies including exercise (supervised or unsupervised), acupuncture, and manual treatments (osteopathy and chiropractic).

- Psychological interventions including cognitive-behavioural therapy (CBT).

A sham facet joint injection and a corticosteroid injection delivered other than to the facet joints was considered to be a sham procedure. Injection of corticosteroid delivered other than to a facet joint without a sham facet joint injection was considered as conservative treatment.

\section{Types of outcome measures}

We considered trials reporting at least one of the following:

- Symptom relief based on pain.

- Back specific functional status (disability).

We included trials that included outcomes for short term (4 weeks), medium term (3 months) and long term (6 months or longer). Where there are other outcomes listed, we selected the closest matching to our categories.

We considered the following outcomes:

- Pain-measured by Visual Analogue Scale (VAS), Numerical Rating Scale (NRS) or McGill pain questionnaire or similar.

- Disability-measured by Oswestry disability index (ODI), Roland-Morris disability questionnaire (RMDQ), Million VAS disability score or Sickness Impact Profile (SIP) or similar.

We considered the following secondary outcomes:

- Adverse events.

\section{Search methods for identification (electronic/other resources)}

We used the search strategy developed by the Cochrane Back Review Group [22] and Chapter six 'Searching for Studies' of the Cochrane Handbook [23].
The following databases were searched for relevant studies:

- Medline

- EMBASE

- CINAHL

- CENTRAL

- Index to chiropractic literature

In addition, citation tracking of the studies retrieved by the search was conducted until no new studies were found. Ongoing trials were identified through the WHO International Clinical Trials Registry Platform (http://www.who. int/ictrp/en/) and ClinicalTrials.gov websites. Details of the search strategies are provided in the appendices (Appendix 1, available online as Supplemental Digital Content...).

\section{Data collection and analyses}

For each of the steps the two reviewers (RV, RB) independently selected studies, assessed the risk of bias, extracted data and resolved differences by consensus bringing in a third review author (HS or DE) when disagreements persisted.

\section{Selection of studies}

The two review authors screened the titles and abstracts after which the full text of potentially relevant studies were then retrieved for the final selection of eligible studies.

\section{Data extraction and management}

The two review authors independently extracted the data using standardised data extraction forms. The following information was collected:

- Study characteristics (aims of the study, study design, randomisation).

- Population characteristics-(patient population source or setting, study inclusion and exclusion criteria, duration of low back pain, diagnostic criteria, age, sex, country).

- Intervention characteristics-(description and types of corticosteroid, dose).

- Comparator characteristics-(description of comparator, duration, frequency).

- Outcome data-(pain intensity and disability at short term, medium term and long term).

- Number of participants assessed, number of dropouts.

- Statistical methods and results.

- Adverse events. 
Fig. 1 Preferred reporting items for systematic reviews and meta-analyses (PRISMA) flow chart

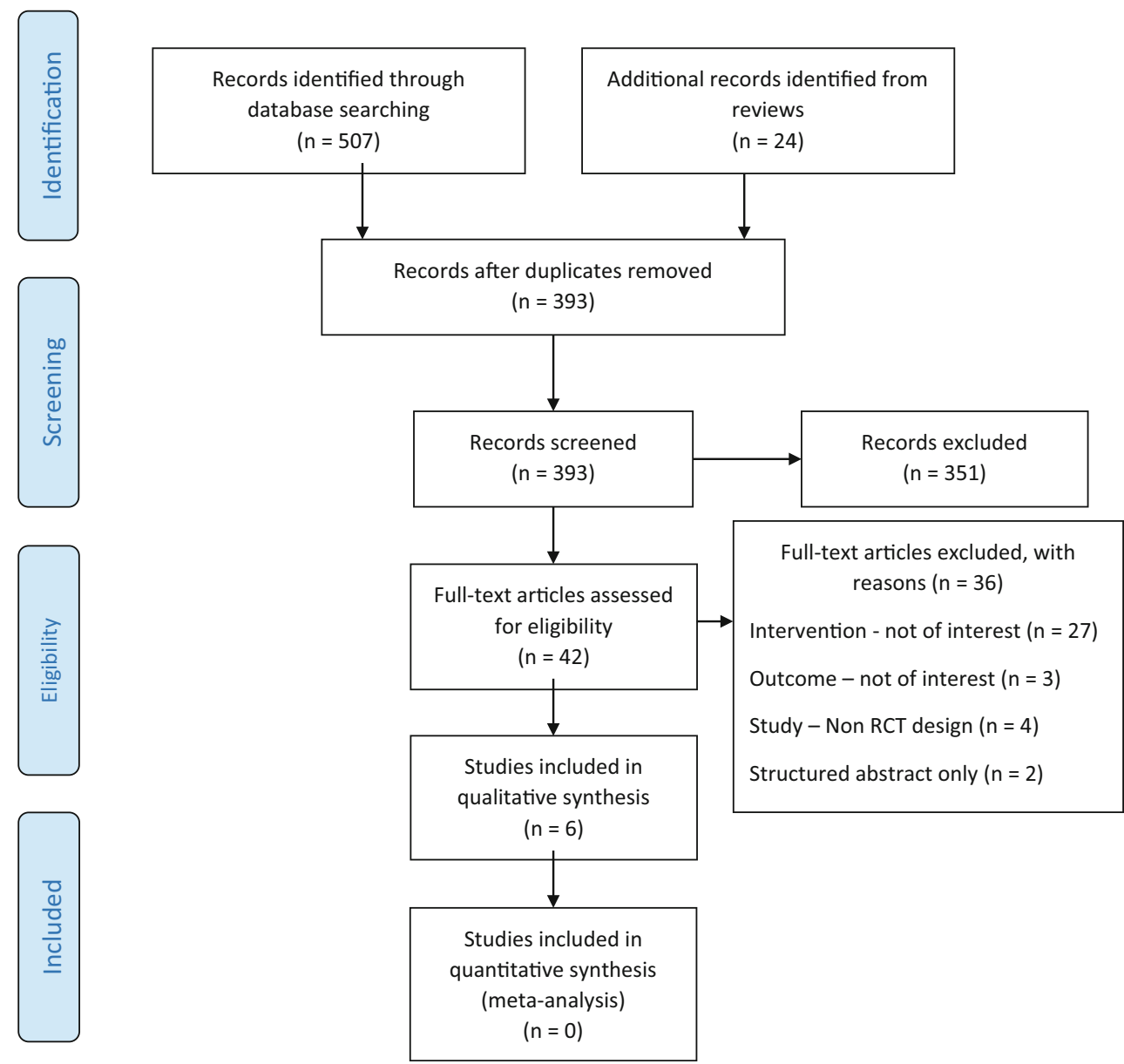

\section{Assessment of risk of bias in included studies}

Two review authors independently assessed the risk of bias. Disagreements that could not be resolved were referred to a third review author (HS). The risk of bias assessment tool recommended by The Cochrane Collaboration $[23,24]$ and the Cochrane Back Review Group's updated method guidelines [22] were used. Studies were characterised as 'Low Risk', 'High Risk', or 'Unclear Risk' of bias for each of the criteria. A study with a low risk of bias was defined as having low risk on six or more of the items and no fatal flaws. A study was defined as having unclear risk of bias if one or more of the criteria did not have enough information.

\section{Data synthesis}

Heterogeneity between the included studies was explored by looking at the methodologies and outcomes being considered. We planned, where possible, to do meta-analyses. Heterogeneity in how the research questions were framed meant this was not possible. As such, we present a narrative synthesis of the available data.

\section{Results}

We identified 507 articles from electronic databases and an additional 24 from related systematic reviews. After removal of duplicates there were 393 unique articles which were screened for inclusion. We retrieved 42 full papers; 36 of these were excluded leaving six included studies. See Fig. 1. PRISMA flow diagram [25].

\section{Included studies}

We included six trials with a total of $N=434$ participants (range 18-109 participants); Lilius [26], Carette [27], Mayer [28], Celik [29], Kawu [30] and Ribeiro [31].

The inclusion criteria were variable (Table 1). Two trials (Carette [27], Mayer [28]) included a diagnostic injection, into the facet joints, one trial, (Ribeiro [31]) used a combination of clinical and radiological assessment. The remaining three Lilius [26], Celik [29], and Kawu [30] used a clinical assessment only. The inclusion criteria fall under four broad headings these are: pain intensity or duration, physical tests, diagnostic tests, or more general criteria (see Table 1). 


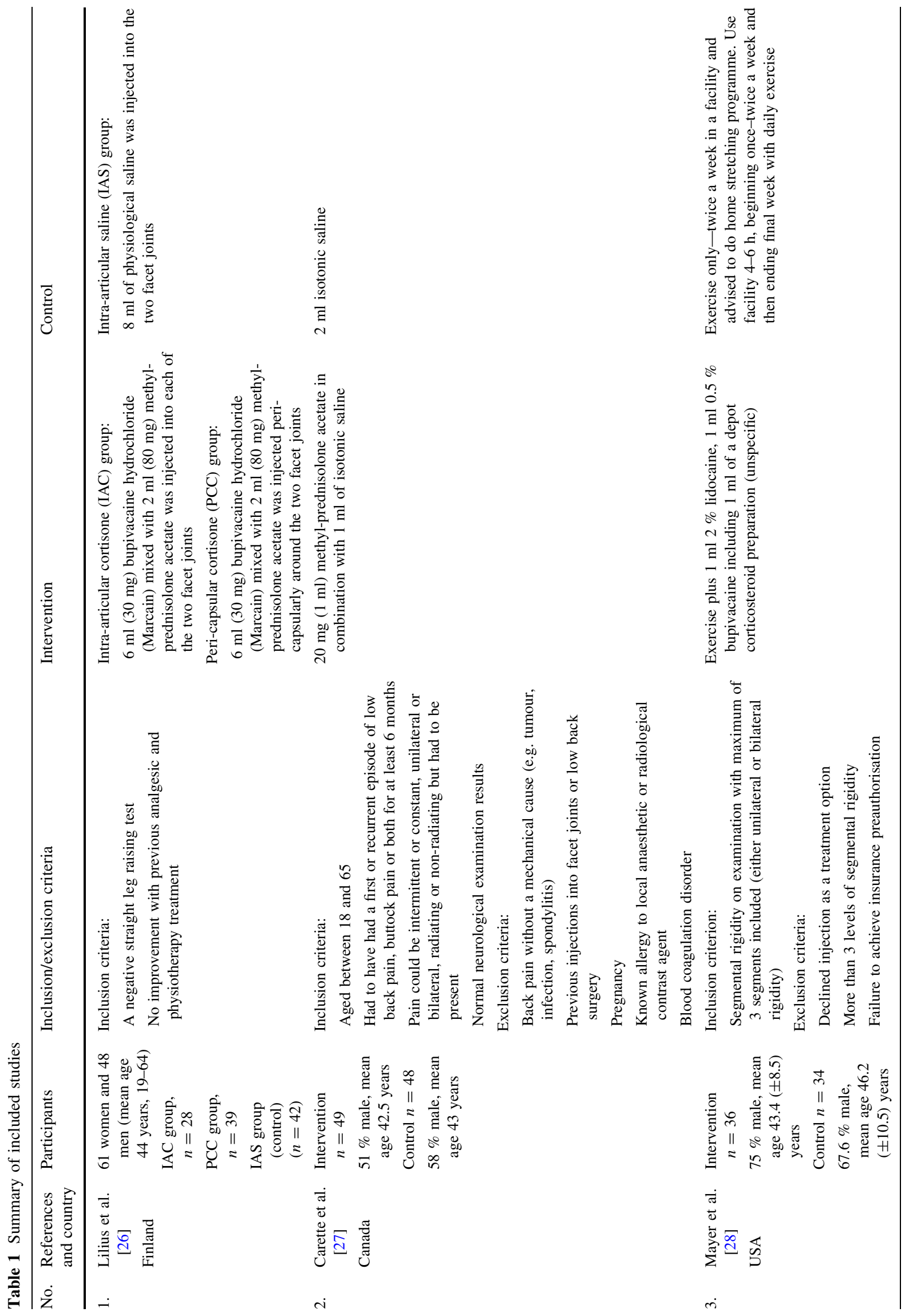




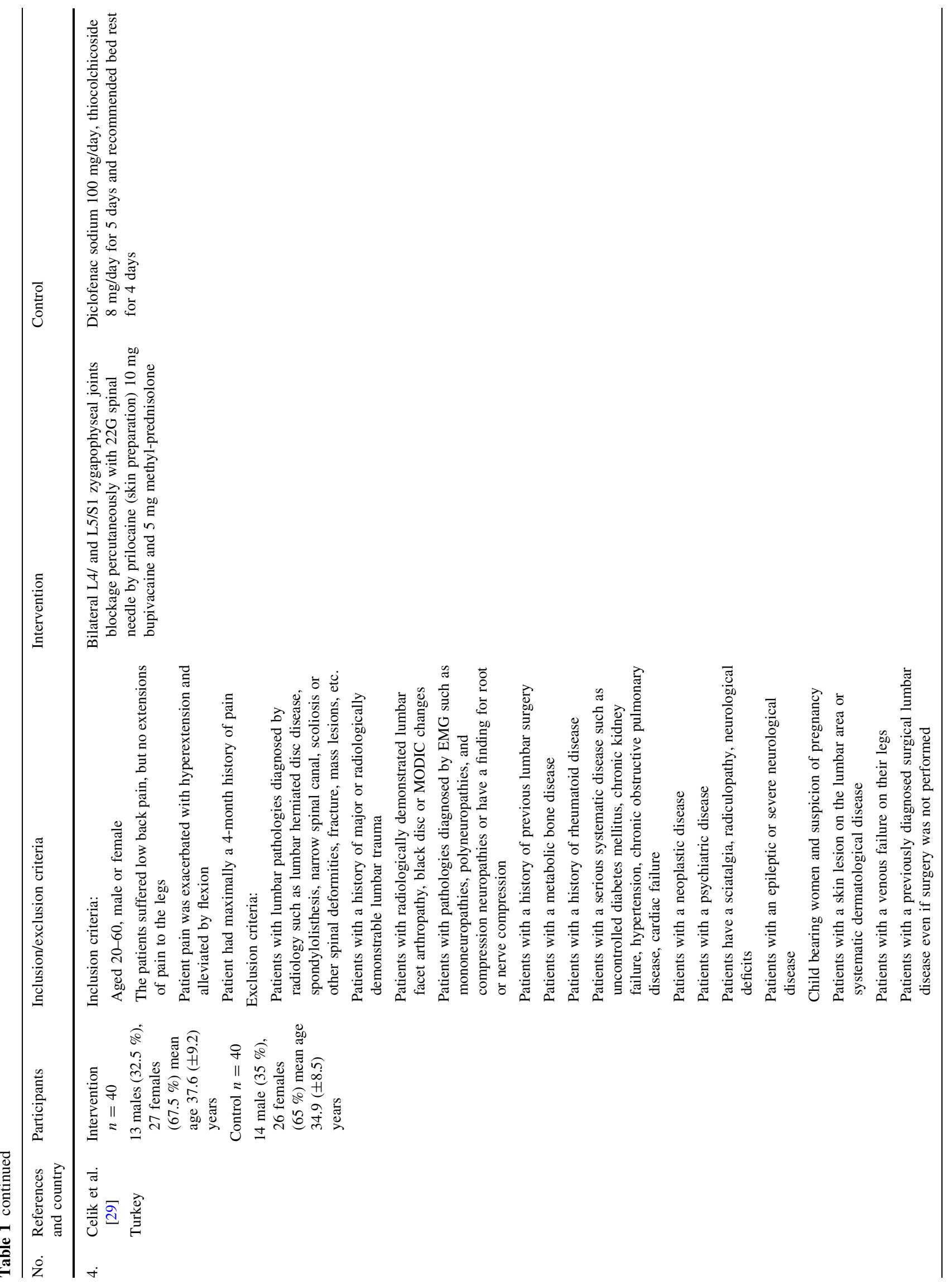




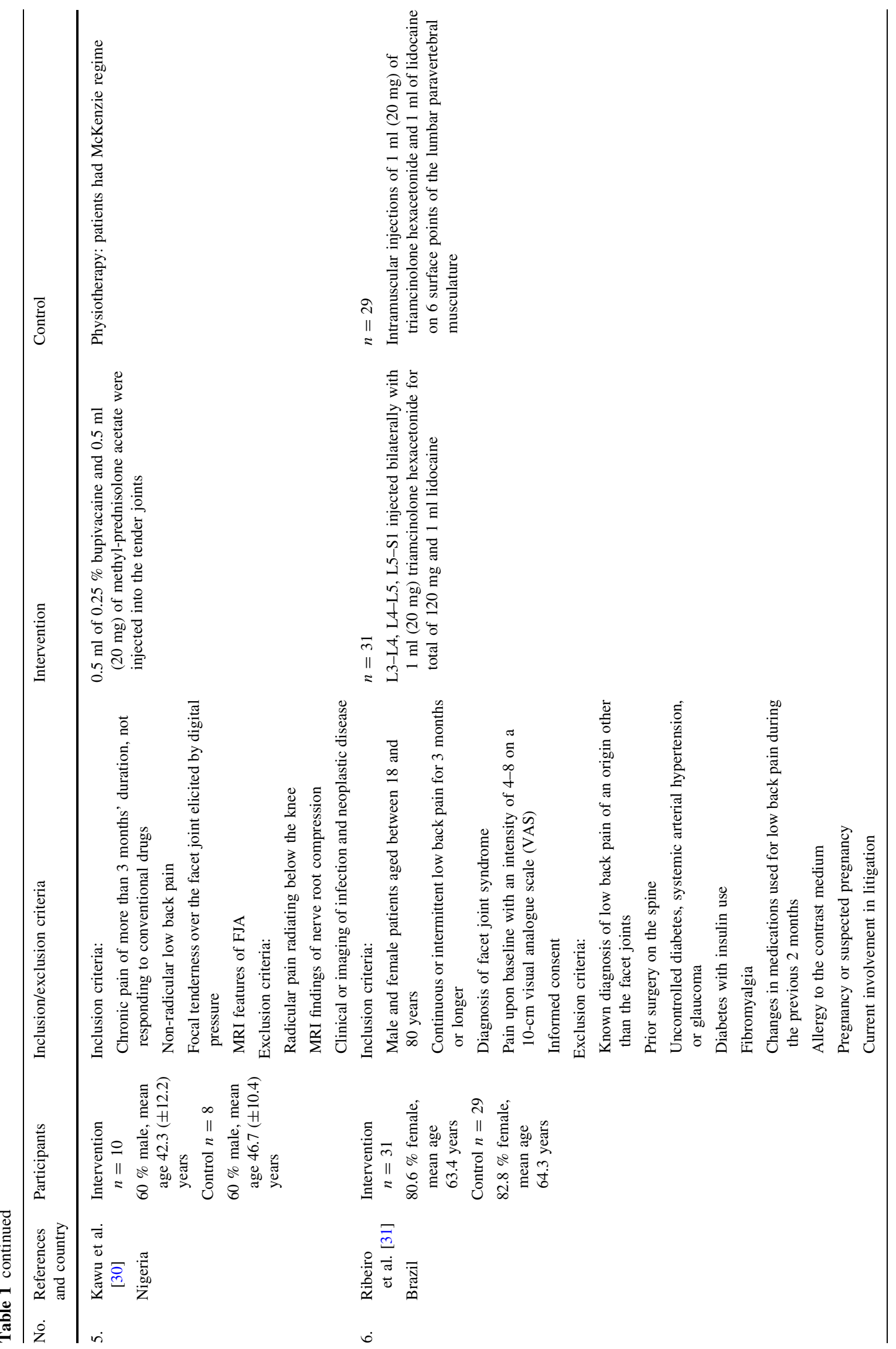




\section{Injection procedures and injectate}

All six trials used different injection procedures with variations in the number of joints injected and whether they are injected unilaterally or bilaterally. Lilius [26] had two intervention groups who either had injections into the facet joints (intra-articular) or injections 'around' the facet joints (peri-capsular). These two groups were pooled for the final comparison.

The injectate used varied in volume and content. Three trials used a combination of bupivacaine hydrochloride (local anaesthetic) and methyl-prednisolone (corticosteroid) in various volumes and concentrations (Lilius [26], Celik [29], Kawu [30]). Carette used a combination of methyl-prednisolone and saline (no local anaesthetic). Mayer et al. used a combination of bupivacaine and a nonspecified depot preparation corticosteroid. Ribeiro [31] used a combination of triamcinolone hexacetonide and lidocaine (Table 1).

\section{Sham/placebo controls}

Two trials Lilius [26] and Carette [27] used intra-articular saline as a placebo control, whilst Ribeiro [31] used active injections into para-spinal muscles as a sham control.

\section{Conservative treatments}

Three trials include a 'conservative treatment' as a control. One was a drug regime and at least 4 days bed rest (Celik [29]). In the other two trials the control treatment was a physical therapy one based on a McKenzie regime (Kawu [30]) and the other, facility based, exercises and advice to use stretching exercises at home (Mayer [28]). Two trials, Celik [29] and Kawu [30], used conservative treatment as an alternative to injections whilst Mayer [28] added injections to conservative treatment.

Two of the trials included a sample size calculation for their primary outcomes (Carette [27], Ribeiro [31]). Reason for incomplete follow-up was not reported in one study (Carette [27]), four studies had no loss at follow-up (Lilius [26], Mayer [28], Celik [29], Kawu [30]), one study (Ribeiro [31]) reported four dropouts, three missed followup and one, in the intervention group, died (not related to study).

Three trials reported adverse events. Lilius et al. [26], reported 'few' side effects but do not specify what they were. Carette et al. [27], report some localised pain near injection site. Ribeiro et al. [31] report adverse events, noting there were no significant differences between groups. These included; post-procedure pain $(n=9)$, cutaneous hypochromia $(n=1)$, increase in blood glucose levels $(n=5)$, vaginal bleeding $(n=3)$, dizziness $(n=3)$ and nausea $(n=3)$. In addition, one control group patient had a serious adverse event; gastrointestinal bleeding, which required endoscopic therapy. They also note that one patient in the intervention group had a fall after a follow-up visit that caused an aggravation of the patient's back pain.

\section{Excluded studies}

We excluded 36 studies which included Kennedy, 2013 and Hayes, 2006 which were excluded as there was only an abstract available [32, 33]. Contact was made with the lead author of the Kennedy paper who is in the process of submitting a manuscript. Brief details of the excluded studies are provided in the appendices (Appendix 2, available online as Supplemental Digital Content...).

\section{Measures of outcome (i.e. pain and disability)}

All six of the trials report on pain and disability outcomes (Table 2). All six of the trials used a visual analogue scale for pain, some of these are well defined with anchors described but others are less specific. Carette, also included the McGill pain questionnaire from which the 'mean present pain intensity' was taken as the variable of interest for this review.

Disability was measured with a variety of tools. Two trials included the Oswestry Disability Questionnaire with the first noting that they used a modified version and the second quotes they used the 'Oswestry disability index' (Celik [29], Kawu [30]). The four remaining trials all used different tools: Lilius et al. uses an undefined measure based on six physical actions; Carette et al. used a modified Sickness Impact Profile (SIP) measure with two of the original variables removed (eating and communicating); Mayer et al. used the Million VAS, a visual analogue scale based on 15 questions related to activities of daily living, and finally Ribeiro et al. used a Roland-Morris Disability Questionnaire (Table 2).

\section{Length of follow-up}

End of follow-up was between 5 and 7 weeks in Mayer, 3 months in Lilius, 24 weeks in Ribeiro and 6 months in Carette, Celik and Kawu (Table 2).

\section{Quality assessment profiles}

Figure 2 includes a quality assessment profile for each of the included trials. These are summarised below. 


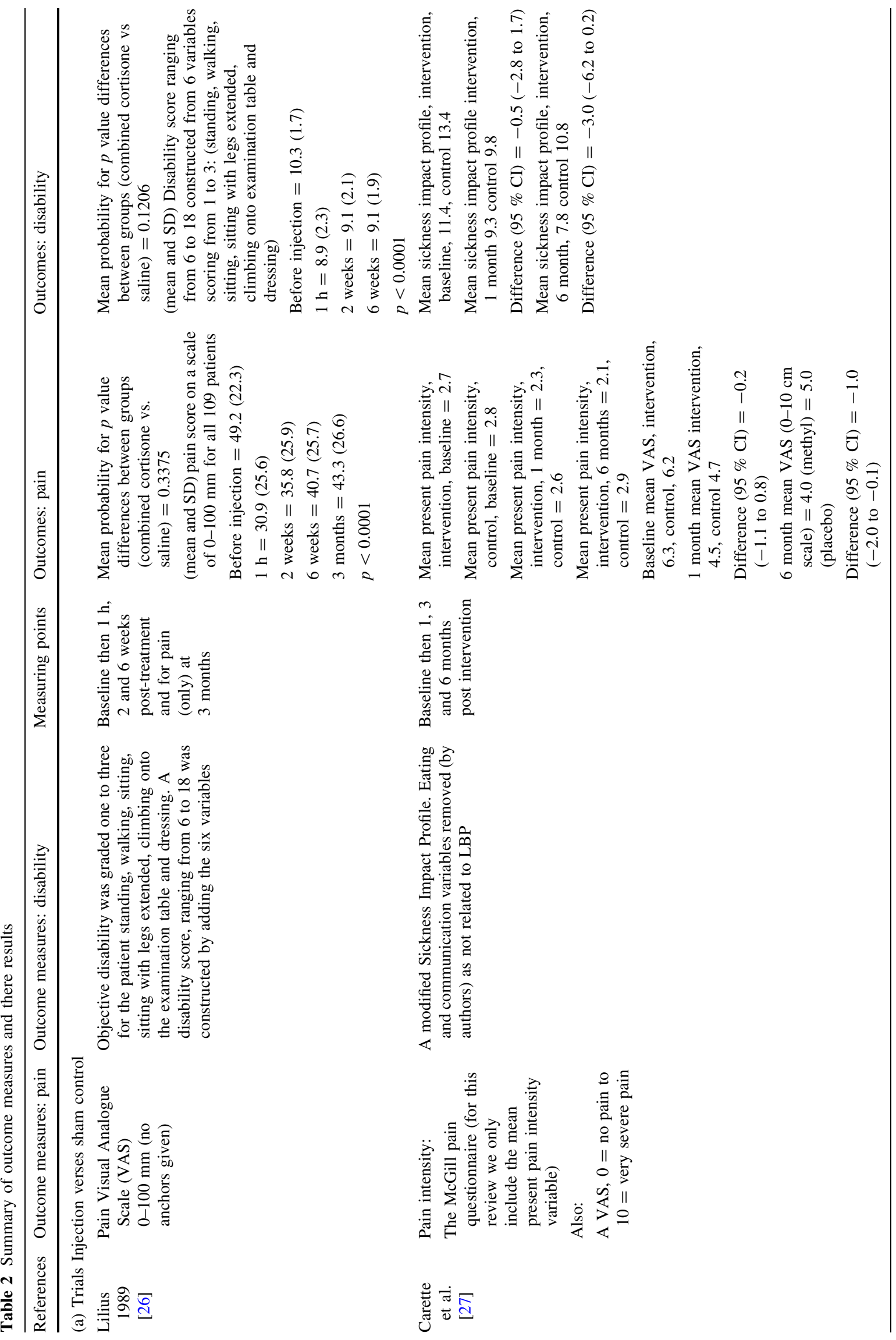




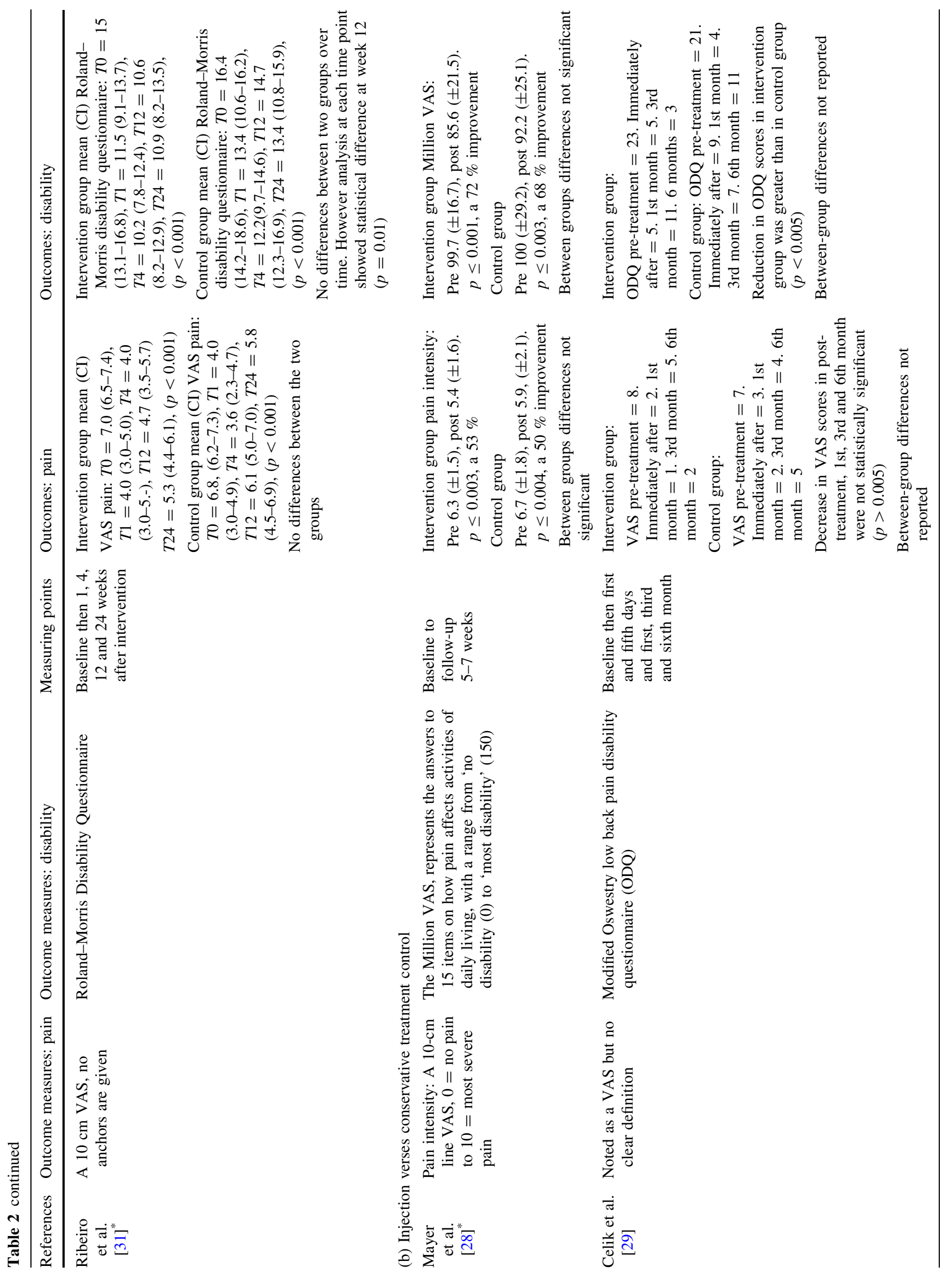




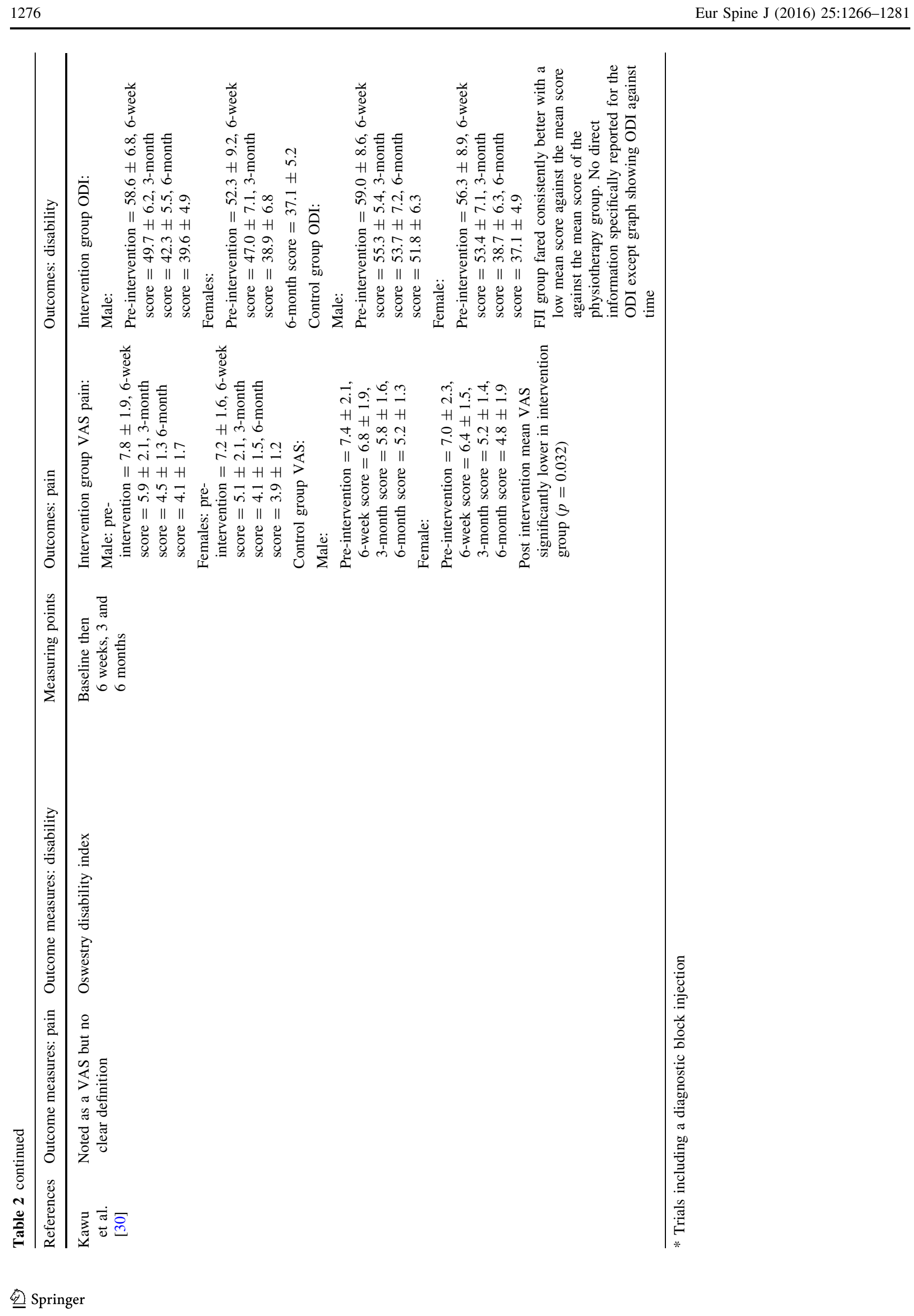


Fig. 2 Risk of bias assessments for included trials

\begin{tabular}{|c|c|c|c|c|c|c|}
\hline & $\begin{array}{l}\text { Lilius } \\
1989 \\
\end{array}$ & $\begin{array}{c}\text { Carette } \\
1991 \\
\end{array}$ & $\begin{array}{c}\text { Mayer } \\
2004\end{array}$ & $\begin{array}{l}\text { Celik } \\
2011 \\
\end{array}$ & $\begin{array}{l}\text { Kawu } \\
2011 \\
\end{array}$ & $\begin{array}{c}\text { Ribeiro } \\
2013 \\
\end{array}$ \\
\hline Random Sequence Generation & ? & + & $\odot$ & ? & ? & + \\
\hline Allocation concealment & ? & ? & - & ? & ?? & + \\
\hline Blinding of participants & ? & + & - & C) & - & + \\
\hline Blinding of personnel/care providers & ? & + & $\odot$ & $\odot$ & $\odot$ & - \\
\hline Blinding of outcomes assessors & + & + & - & - & - & + \\
\hline Incomplete outcome data & + & + & + & + & + & + \\
\hline Selective outcome reporting & + & + & + & + & + & + \\
\hline Group similarity at baseline & + & + & + & + & + & + \\
\hline Co-interventions & + & ? & ? & + & ? & - \\
\hline Compliance & + & + & + & ? & ? & + \\
\hline Intention-to-treat analysis & + & C & + & ? & + & + \\
\hline Timing of outcome assessments & + & + & ? & + & + & + \\
\hline Other bias & + & + & + & (?) & + & + \\
\hline
\end{tabular}

\section{Allocation (selection bias)}

There was generally low-risk allocation bias across all studies with concealment maintained. However, there were two studies from which it was not possible to determine risk of allocation bias as there was no description of the process. One study (Mayer) was at high risk of allocation bias as patients were allocated to the two groups in an alternating manner (see Fig. 2).

\section{Blinding (performance bias and detection bias)}

One study (Lilius) was unclear on its method of blinding and whether participants were truly blinded to what they were receiving.

In Carette's study, the participants were blinded as to which treatment they were receiving with the syringe covered in tin foil for both control and intervention. The care providers and assessors were also blinded.

Celik et al. had high risk of blinding bias due to the control being exercise or physiotherapy, the participants could not be blinded to the process.

Ribeiro was partially blinded with the participants; however, the care providers were not blinded as they were injecting the control and treatment in different anatomical sites.

\section{Incomplete outcome data (attrition bias)}

In two studies (Lilius and Carette) there were patients who did not attend the follow-up examination post-treatment; however, this was deemed to be insignificant to the outcomes drawn by the paper as they were from both the control and intervention groups. Similarly, in another study
(Ribeiro), there was low risk of attrition bias as equal numbers were lost from the control and intervention groups. Celik et al. studies were low risk as no patients left the study.

\section{Selective reporting (reporting bias)}

These are generally low risk across the studies with the prespecified set of outcomes being reported.

\section{Effects of interventions}

Here we present the outcomes of the trials split into two categories, which are:

- Injection versus sham control.

- Injection versus conservative treatment control.

Those including a diagnostic injection will be highlighted. Understanding how differences in participant selection, and the comparators used in these trials is critical to understanding how the results might be interpreted and where data pooling might be possible. We have sought to clarify the differences and similarities in Fig. 3.

Below we summarise the outcome findings from the trials details can be found in Table 2 .

Injection versus sham control (pain and disability outcomes)

Three trials have an injection verses a sham injection control (Lilius [26], Carette [27], Ribeiro [31]) with one (Carette [27]) using a diagnostic injection before randomisation (Table 2a). In the Carette trial 190 patients were given the diagnostic injection (lidocaine), 110 
Fig. 3 Summary of designs of included studies. Entry criteria; clinical clinical assessment only, radiographic clinical plus radiological change, block clinical plus positive diagnostic block, acute pain $<3$ months, chronic pain more than 3 months: interventions, $L A$ local anaesthetic, NSAID nonsteroidal anti-inflammatory drugs, McKenzie McKenzie exercise technique

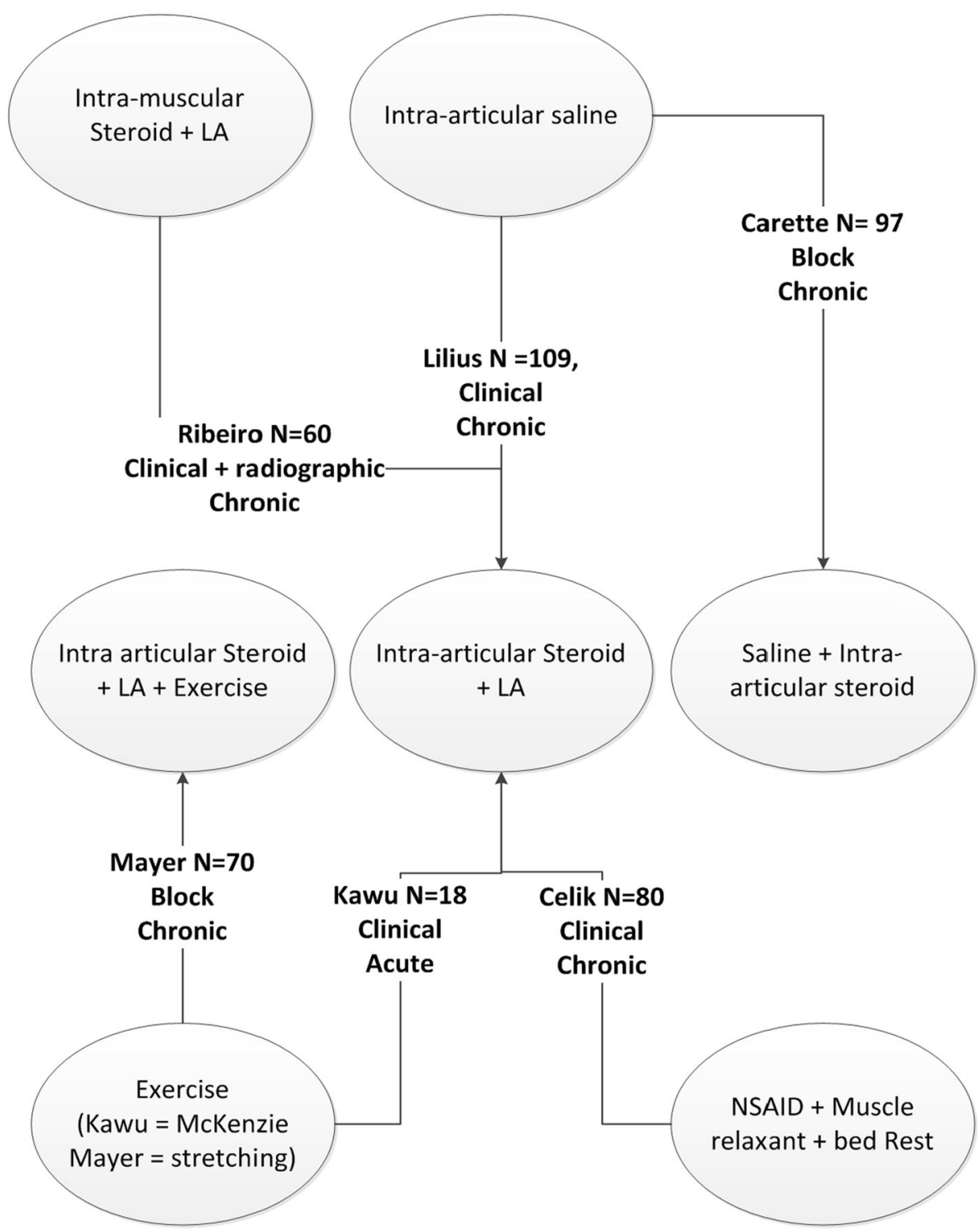

patients met the inclusion criterion of a $50 \%$ or more reduction in pain, two of these had no recurrence of pain and seven chose not to participate. Therefore, 101 patients entered the randomised phase (intervention, $n=51$, placebo, $n=50$ ). Four patients, two in each arm, were later excluded from analysis for not meeting inclusion criteria.

None of these trials report significant differences in pain or disability between groups at their pre-specified primary outcome. Carette [27] reports significant between-group differences in the visual analogue pain score (mean difference $-1.0,95 \% \mathrm{CI}-2.0$ to -0.1$)$ and the sickness impact profile (physical dimension) (mean difference -3.0, $95 \%$ CI -6.2 to 0.2 ) at final follow-up (6 months) [27]. Ribeiro report statistically significant differences in role physical sub-scale of SF-36 over 24 weeks ( $p=0.023)$, 'improvement percentage' at 1 and 24 weeks $(p=0.03$ and $p=0.04)$, pain improvement at week one $(p=0.029)$, Diclofenac use $(p=0.04)$, and Roland-Morris Disability score at 12 weeks $(p=0.01)$ [31].

Injection versus conservative treatment control (pain and disability outcomes)

Three trials have injection verses a conservative treatment (Mayer [28], Celik [29], Kawu [30]) with one (Mayer [28]) using a diagnostic injection (see Table 2b). One trial (Mayer [28]) reports no significant differences between groups for either pain or disability at follow-up (5-7 weeks). The results in the Kawu trial are presented within group, but they do state that there was a significant between-group improvements in pain (intervention, males, mean $4.1 \pm 1.7$, females $3.9 \pm 1.2$ and control males 
$5.2 \pm 1.3$, females $4.8 \pm 1.9, p=0.032)$ at 6 -month follow-up. For disability outcomes they report a significant improvement over time $(p=0.013)$ [30]. Celik [29] only report within-group data; there are no between-group results reported (Table 2).

\section{Discussion}

Our systematic review revealed that there were few trials of intra-articular facet joint injections. That no two trials have tested similar hypotheses means it is difficult to draw any clinically useful conclusions.

There is a wide range in the quality of the six trials reported here. Only two, (Carette [27], Ribeiro [31]) reported a sample size calculation, and had clear information on randomisation and only one of these provided information about allocation-concealment [31].

There is no consistent pattern of benefit across trials. Some show levels of improvement whilst others find none. Indeed, patients improve with and without the intervention treatment. In the Lilius study, they found there was improvement in pain and disability across all three intervention groups [26]. Similarly, in the Ribeiro trial both treatments are found to be equally effective with only a slightly larger improvement following intra-articular steroids over intramuscular injections in some secondary outcomes; but without a consistent pattern. Both groups were found to have improvement with regard to functional status; however, the difference between them was not statistically significant until week 12 . The co-intervention intake was significantly different between the two groups with diclofenac intake reduced in the experimental group [31].

Mayer suggests that corticosteroid injections in conjunction with supervised stretching exercises may improve pain or disability outcomes rather than exercise alone. However, they concluded that facet joint injections do not explain the improved pain and disability outcomes observed in the control and treatment groups as the preand post-trial measures were comparable and therefore could not be attributed to the pharmacological profile of the cortisone taking effect. Even though the range of lumbar movement was observed to be significantly improved in the treatment group. The study also stated possible bias due to the difference in segmental rigidity of participants between both groups despite randomisation, but due to the range of movements being opposite in both groups, they disregarded this as a potential source of bias [28].

The Kawu trial does report a positive significant result for both pain and disability outcomes at 6 months [30]. The control, conservative treatment, in this trial was physiotherapy (McKenzie technique) this technique encourages extension of the back. There is now a growing body of evidence that this will just make the pain worse for those with chronic low back pain particularly those with facet joint pain. Thus it maybe that the lack of improvement in pain and disability outcomes in the control group was due to exacerbation of the patients back pain problems by the exercises given [34].

Overall completeness of evidence in terms of applicability, from the current evidence, does not support the use of intra-articular facet joint injections. However, as statistically significant between-group differences are reported in some secondary outcomes (all favouring intervention) in some of the studies there is merit in further investigating their potential effectiveness.

In the majority of studies presented in this review, no adverse events or side effects associated with the treatments were reported. Transient symptoms such as increased low back discomfort were noted though most trials were small and not designed to evaluate adverse events, so no clear conclusion can be drawn regarding the risks of facet joint injections. It is important that future trials record any adverse events while using these procedures in order to appropriately weigh any benefits against potential risks.

It is possible that in searching studies for this review, relevant but unpublished trials may have been missed, which are often likely to be small studies without positive results, leading to publication bias. However, because the majority of published trials was small and did not show a positive effect, publication bias does not seem to be a big problem in this review.

Due to the study selection criterion used, including only trials of intra-articular facet joint injections, this review included fewer studies than similar reviews [9, 35]. Many excluded RCTs used different types of injection therapy and denervation procedures. However, the main conclusions of our review appear to be similar to recent systematic reviews, which generally report a paucity of highquality RCTs on injection therapy for lower back pain and insufficient evidence to support their use.

\section{Conclusions}

Facet joint injections are commonly used; however, there is insufficient high-quality evidence to support their usage over placebo/sham-controlled procedures or conservative therapy for lower back pain. Further investigations are required to prove their efficacy in targeting lower back pain, which is attributed to facet joints and this must be balanced against any potential adverse events as a result of the injections.

Further randomised controlled trials of higher methodological standard comparing facet joint injection with a 
sham/placebo control or conservative treatment are needed from which to base any conclusion on the effectiveness of facet joints in improving pain and disability outcomes.

Acknowledgments This project benefited from facilities funded through Birmingham Science City Translational Medicine Clinical Research and Infrastructure Trials Platform, with support from Advantage West Midlands. The team wish to acknowledge the NIHR (HTA Project: 11/31/01-Facet Feasibility) whilst not funding this project the grant is covering the salary of one of the team (DE).

\section{Compliance with ethical standards}

Conflict of interest MU is principal investigator and HS is a coinvestigator for a trial exploring the feasibility on doing a randomised controlled trial testing the addition of intra-articular facet joint injections to best usual care (HTA Project: 11/31/01-Facet Feasibility). DE is also working on this trial as a researcher. The other authors report no conflicts of interest.

Open Access This article is distributed under the terms of the Creative Commons Attribution 4.0 International License (http://crea tivecommons.org/licenses/by/4.0/), which permits unrestricted use, distribution, and reproduction in any medium, provided you give appropriate credit to the original author(s) and the source, provide a link to the Creative Commons license, and indicate if changes were made.

\section{References}

1. Vos T, Flaxman AD, Naghavi M, Lozano R, Michaud C, Ezzati M, Shibuya K, Salomon JA, Abdalla S, Aboyans V et al (2012) Years lived with disability (YLDs) for 1160 sequelae of 289 diseases and injuries 1990-2010: a systematic analysis for the Global Burden of Disease Study 2010. Lancet 380(9859):2163-2196. doi:10.1016/ S0140-6736(12)61729-2

2. Dagenais S, Caro J, Haldeman S (2007) A systematic review of low back pain cost of illness studies in the United States and internationally. Spine J 8(1):8-20. doi:10.1016/j.spinee.2007.10.005

3. NICE (2009) Low back pain: early management of persistent non-specific low back pain. National Institute for Health and Care Excellence. https://www.nice.org.uk/guidance/cg88/resources/ guidance-low-back-pain-pdf. Accessed 08 Aug 2015

4. Manchikanti L, Singh V (2002) Review of chronic low back pain of facet joint origin. Pain Physician 5(1):83-101

5. Lewinnek GE, Warfield CA (1986) Facet joint degeneration as a cause of low back pain. Clin Orthop 213:216-222

6. Dreyfuss PH, Dreyer SJ, Herring SA (1995) Lumbar zygapophysial (facet) joint injections. Spine 20(18):2040-2047

7. Bogduk N, Wilson AS, Tynan W (1982) The human lumbar dorsal rami. J Anat 134(Pt 2):383-397

8. Manchikanti L, Boswell MV, Singh V, Pampati V, Damron KS, Beyer CD (2004) Prevalence of facet joint pain in chronic spinal pain of cervical, thoracic, and lumbar regions. BMC Musculoskelet Disord 5(15):15. doi:10.1186/1471-2474-5-15

9. Chou R, Loeser JD, Owens DK, Rosenquist RW, Atlas SJ, Baisden J, Carragee EJ, Grabois M, Murphy DR, Resnick DK, Stanos SP, Shaffer WO, Wall EM (2009) Interventional therapies, surgery, and interdisciplinary rehabilitation for low back pain: an evidence-based clinical practice guideline from the American Pain Society. Spine 34(10):1066-1077. doi:10.1097/BRS. 0b013e3181a1390d
10. Manchikanti L, Abdi S, Atluri S, Benyamin RM, Boswell MV, Buenaventura RM, Bryce DA, Burks PA, Caraway DL, Calodney AK et al (2013) An update of comprehensive evidence-based guidelines for interventional techniques in chronic spinal pain. Part II: guidance and recommendations. Pain Physician 16(2 Suppl):S49-S283

11. Bellamy N, Campbell J, Robinson V, Gee T, Bourne R, Wells G (2006) Intraarticular corticosteroid for treatment of osteoarthritis of the knee. Cochrane Database Syst Rev 2:CD005328

12. Buchbinder R, Green S, Youd JM (2003) Corticosteroid injections for shoulder pain. Cochrane Database Syst Rev 1:CD004016

13. Zhang W, Doherty M, Arden N, Bannwarth B, Bijlsma J, Gunther KP, Hauselmann HJ, Herrero-Beaumont G, Jordan K, Kaklamanis $\mathrm{P}$, Leeb B, Lequesne $\mathrm{M}$, Lohmander S, Mazieres B, Martin-Mola E, Pavelka K, Pendleton A, Punzi L, Swoboda B, Varatojo R, Verbruggen G, Zimmermann-Gorska I, Dougados M, Therapeutics ESCfICSI (2005) EULAR evidence based recommendations for the management of hip osteoarthritis: report of a task force of the EULAR Standing Committee for International Clinical Studies Including Therapeutics (ESCISIT). Ann Rheum Dis 64(5):669-681

14. Machado E, Bonotto D, Cunali PA (2013) Intra-articular injections with corticosteroids and sodium hyaluronate for treating temporomandibular joint disorders: a systematic review. Dental Press J Orthod 18(5):128-133

15. Colen S, Geervliet P, Haverkamp D, Van Den Bekerom MP (2014) Intra-articular infiltration therapy for patients with glenohumeral osteoarthritis: a systematic review of the literature. Int J Shoulder Surg 8(4):114-121. doi:10.4103/0973-6042. 145252

16. van Vliet-Daskalopoulou E, Jentjens T, Scheffer RT (1987) Intraarticular rimexolone in the rheumatoid knee: a placebo-controlled, double-blind, multicentre trial of three doses. $\mathrm{Br} \mathrm{J}$ Rheumatol 26(6):450-453

17. Barnes PJ, Adcock I (1993) Anti-inflammatory actions of steroids: molecular mechanisms. Trends Pharmacol Sci 14(12): 436-441

18. Kidd BL, Morris VH, Urban L (1996) Pathophysiology of joint pain. Ann Rheum Dis 55(5):276-283

19. Jack K, McLean SM, Moffett JK, Gardiner E (2010) Barriers to treatment adherence in physiotherapy outpatient clinics: a systematic review. Man Ther 15(3):220-228. doi:10.1016/j.math. 2009.12.004

20. Mars T, Ellard D, Antrobus J, Cairns M, Underwood M, Haywood K, Keohane S, Sandhu H, Griffiths F (2015) Intraarticular facet injections for low back pain: design considerations, consensus methodology to develop the protocol for a randomized controlled trial. Pain Physician 18(5):473-493

21. Sehgal N, Dunbar EE, Shah RV, Colson J (2007) Systematic review of diagnostic utility of facet (zygapophysial) joint injections in chronic spinal pain: an update. Pain Physician 10(1):213-228

22. Furlan AD, Pennick V, Bombardier C, van Tulder M, Editorial Board CBRG (2009) 2009 updated method guidelines for systematic reviews in the Cochrane Back Review Group. Spine 34(18):1929-1941. doi:10.1097/BRS.0b013e3181b1c99f

23. Higgins JPT GSe (2011) The Cochrane collaboration, 2011. Cochrane Handbook for Systematic Reviews of Interventions Version 510. Available from www.cochrane-handbook.org. Accessed March 2011

24. Higgins JP, Altman DG, Gotzsche PC, Juni P, Moher D, Oxman AD, Savovic J, Schulz KF, Weeks L, Sterne JA, Cochrane Bias Methods G, Cochrane Statistical Methods G (2011) The Cochrane collaboration's tool for assessing risk of bias in randomised trials. BMJ 343:d5928. doi:10.1136/bmj.d5928 
25. Moher D, Liberati A, Tetzlaff J, Altman DG, Group P (2009) Preferred reporting items for systematic reviews and meta-analyses: the PRISMA statement. BMJ 339:b2535. doi:10.1136/bmj. b2535

26. Lilius G, Laasonen EM, Myllynen P, Harilainen A, Gronlund G (1989) Lumbar facet joint syndrome: a randomised clinical trial. J Bone Joint Surg Br 71(4):681-684

27. Carette S, Marcoux S, Truchon R, Grondin C, Gagnon J, Allard Y, Latulippe M (1991) A controlled trial of corticosteroid injections into facet joints for chronic low back pain. $\mathrm{N}$ Engl $\mathrm{J}$ Med 325(14):1002-1007

28. Mayer TG, Gatchel RJ, Keeley J, McGeary D, Dersh J, Anagnostis C (2004) A randomized clinical trial of treatment for lumbar segmental rigidity. Spine 29(20):2199-2205

29. Celik B, Er U, Simsek S, Altug T, Bavbek M (2011) Effectiveness of lumbar zygapophysial joint blockage for low back pain. Turk Neurosurg 21(4):467-470

30. Kawu AA, Olawepo A, Salami AO (2011) Facet joints infiltration: a viable alternative treatment to physiotherapy in patients with low back pain due to facet joint arthropathy. Niger J Clin Pract 14(2):219-222. doi:10.4103/1119-3077.84021

31. Ribeiro LH, Furtado RN, Konai MS, Andreo AB, Rosenfeld A, Natour J (2013) Effect of facet joint injection versus systemic steroids in low back pain: a randomized controlled trial. Spine 38(23):1995-2002. doi:10.1097/BRS.0b013e3182a76df1

32. Hayes (2006) Facet blocks for chronic back pain (Structured abstract). HAYES, Inc. http://www.crd.york.ac.uk/CRDWeb/ ShowRecord.asp?AccessionNumber $=32006001570 \& U$ UserID $=0$. Accessed 04 June 2015

33. Kennedy DJ, Stout AA, Conrad B, Smuck M (2013) A randomized, double-blind, placebo-controlled, prospective study of intraarticular lumbar zygapophysial joint corticosteroid injection(s) as treatment of chronic low back pain in a selected population. Phys Med Rehabil 5(9):S286. doi:10.1016/j.pmrj.2013. 08.508

34. Machado LA, de Souza M, Ferreira PH, Ferreira ML (2006) The McKenzie method for low back pain: a systematic review of the literature with a meta-analysis approach. Spine 31(9):E254E262. doi:10.1097/01.brs.0000214884.18502.93

35. Staal JB, de Bie RA, de Vet HC, Hildebrandt J, Nelemans P (2009) Injection therapy for subacute and chronic low back pain: an updated Cochrane review. Spine 34(1):49-59 